\title{
First observation of hemoglobin crete in combination with hemoglobin's in a woman with avascular necrosis of the knee
}

\begin{abstract}
Sickle cell disease comprises a group of genetic disorders characterized by the inheritance of sickle hemoglobin ( $\mathrm{Hb} \mathrm{S}$ ) from both parents, or $\mathrm{Hb} \mathrm{S}$ from one parent and a gene for an abnormal hemoglobin or beta-thalassemia from the other parent. We report the first case of a compound heterozygosity for $\mathrm{HbS}$ and $\mathrm{Hb}$ Crete in a 24 year old Greek woman with bone infarctions as the first symptom.
\end{abstract}

Keywords: disorders, beta-thalassemia, hemoglobin crete, sickle cell disease
Volume 5 Issue 3 - 2017

\author{
Sophia Delicou,' Zoe Palantza,' Efstathios \\ Vavourakis, ${ }^{2}$ Konstantinos Maragkos' \\ 'Hippokrateio General Hospital, Greece \\ ${ }^{2}$ Aghia Sophia Childrens Hospital, Greece
}

Correspondence: Sophia Delicou, Hematologist, Thalassemia and Sickle Cell Unit, Hippokrateio General Hospital Athens, I I4 Vasilissis Sofias, I I527, Greece, Email sophiadelicou@gmail.com

Received: July 31, 2017 | Published: October 18, 2017
Abbreviations: $\mathrm{Hb} \mathrm{S}$, sickle hemoglobin; $\mathrm{HBB}$, globin gene; SCD, sickle-cell disease; HPLC, high performance liquid chromatography; $\mathrm{Hb}$, hemoglobin

\section{Introduction}

Inherited haemoglobin disorders are the most frequent monogenic diseases worldwide. Seven per cent of the world's population is estimated to carry a mutation in the beta $(\beta)$ globin gene (HBB) (GenBank genomic reference sequence NG_000007.3), in a heterozygous state (carrier), while thousands of newborns are affected by a severe haemolgobin disorders. Hemoglobin disorders comprise the $\alpha$ and $\beta$ thalassaemia, sickle-cell disease (SCD) and other hemoglobinopathies. Beta-thalassaemia ( $\beta$-thalassaemia), along with sickle-cell disease (SCD), are the most frequent genetic disorders in Greece, where the mean frequency trait is estimated at $7-8 \%$, and $1-2 \%$, respectively. The majority of $\beta$-thalassaemia genetic defects are point mutations of various frequencies in each ethnic population. In Greece, the most prevalent molecular defect is the IVS I-110 (G>A) or HBB: c. 93-21G $>$ A mutation, followed by $\mathrm{CD} 39(\mathrm{C}>\mathrm{T})$ or c.118C $>\mathrm{T}$, IVS I-1 $(\mathrm{G}>\mathrm{A})$ or $\mathrm{c} .92+1 \mathrm{G}>\mathrm{A}$ and IVSI-6(C>T) or $\mathrm{c} .92+6 \mathrm{~T}>\mathrm{C}$. Hemoglobin Crete is an abnormal hemoglobin of beta chain with high oxygen affinity and neutral and unstable as electrophoretic.

\section{Case presentation}

A 24year old Greek female patient was referred to our department from the region of Crete with a month history of severe bone pains, swelling and severe pain of the right knee and MRI findings of advanced changes of irregular sclerosis and lucency on both sides of the knee joint reflecting numerous prior infarcts (Figure 1). Examination on admission revealed unremarkable vital signs. Cardiorespiratory examination did not show abnormalities. Similarly her clinical examination showed no tenderness or organomegaly. There was however a significant tenderness in right leg with no inflammation clinically. She was also developed severe pain whenever she tried to weight bear.

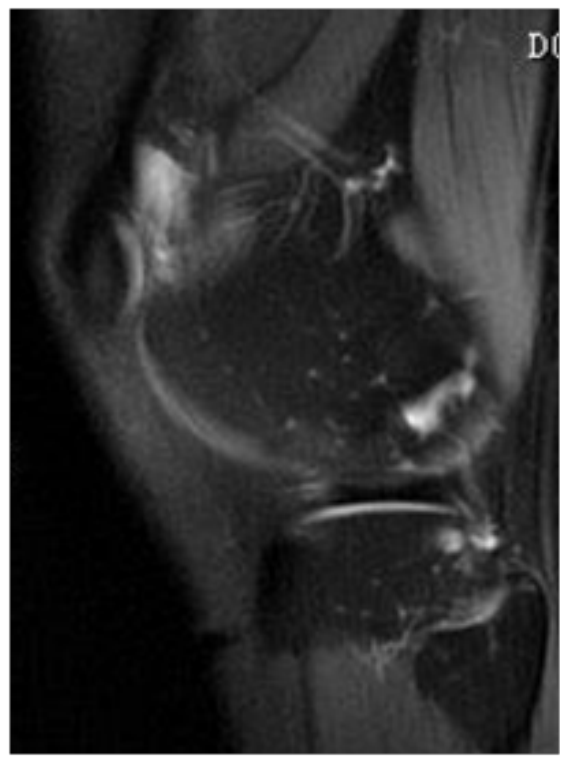

Figure I Irregular sclerosis and lucency on both sides of the knee joint reflecting numerous prior infarcts- stage 2 of osteonecrosis.

Her social and family history was unremarkable. Her father had died in a car accident at the age of 35 and her mother was alive and healthy at the age of 47 . Laboratory data revealed a total white blood cell count of $8.48 \times 10^{3} / \mathrm{ul}$ (62.4\% neutrophils, $28.6 \%$ lymphocytes, 3.7

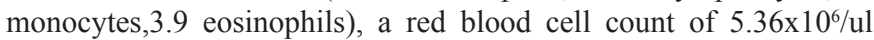
(MCV :60Fl (normal range: $80-99$ ), $\mathrm{MCH}: 20.4 \mathrm{pg}$ (normal range: 27-31), MCHC:30g/dl (normal range: 33-37), RDW: 15\% ( normal range: $11.5-14.5$ ) hemoglobin of $12.2 \mathrm{~g} / \mathrm{dl}($ normal range: $12-18$ ), and a platelet count of $321 \times 10^{3} / \mathrm{uL}$. Serum ferritin was $62 \mathrm{ngr} / \mathrm{ml}$ (normal range:6-81). Peripheral Blood Smear showed microcytosis, hypochromia, anisocytosis, and sickle cells. The result of High Performance Liquid Chromatography (HPLC) showed HbS: 59.6\%, $\mathrm{HbA} 2: 3.8 \%$ and $\mathrm{HbF}: 2.8 \%$ (Figure 2). 


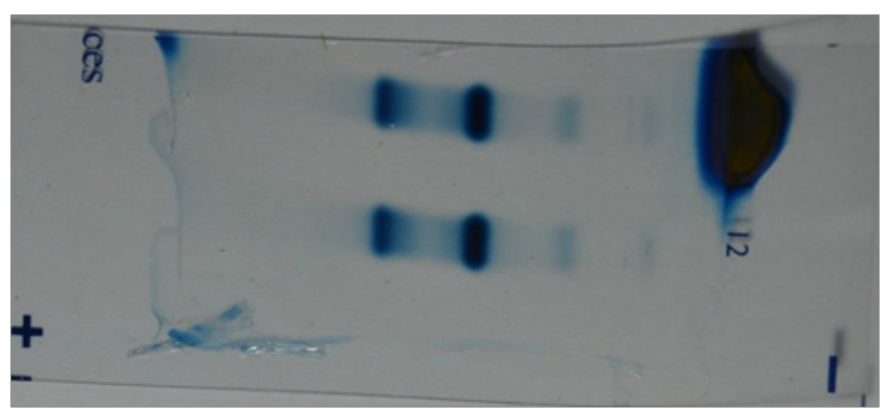

Figure 2 High Performance Liquid Chromatography (HPLC) showed $\mathrm{HbS}$ : 59.6\%, $\mathrm{HbA}$ 2: $3.8 \%$ and HbF: $2.8 \%$ - notice normal hemoglobin A2 levels.

The rest of further laboratory tests, including calcium, PTH, tumor markers, anti-nuclear antibodies, thrombophilia screen test, lupus anticoagulant, cardiolipin antibodies and virology were normal. The hematology indicated that the case was not typical for homozygous sickle cell anemia, most notably because of significant hypochromia and microcytosis and the clinical severity of MRI findings of avascular necrosis of the knee. Complete DNA sequence analysis revealed a single nucleotide substitution c.388G $>$ C. The variant leads to a codon change causing in exon 3, specifically codon 1291368 GCC-->CCC base substitution in exon 3 of the beta-globin gene, leading to the Ala->Pro amino acid change at codon 129 , in the compound heterozygous state with the nucleotide substitution c.20A $>\mathrm{T}$, underlying $\mathrm{HbS}$; her mother had carried the c. $388 \mathrm{G}>\mathrm{C}$, underlying $\mathrm{Hb}$ Crete and we supposed it was assumed that her father had carried an $\mathrm{HbS}$ heterozygoty allele. Known deletions and duplications in the alpha globin gene cluster were excluded, as were known point mutations in the HBA1 and HBA2 genes.

\section{Discussion}

$\beta$-globinopathies are a group of inherited disorders characterized by altered or absent haemoglobin chain synthesis leading to ineffective erythopoiesis, with an autosomal recessive mode of inheritance. They are highly prevalent in populations in the Mediterranean, Middle East, Transcaucasus, Central Asia, Indian subcontinent, and\& Far East, and additionally\& relatively common in populations of African descent. ${ }^{1}$ Hemoglobin Crete, beta 129(H7) Ala>Probeta129 (h7)ala (Figure 3 ) leads to pro, is a new mutant hemoglobin $(\mathrm{Hb})$ with high oxygen affinity that was first discovered identified in a Greek family in various combinations with beta- and delta beta- thalassemia. ${ }^{2}$ Although hematological and HPLC results are normal borderline normal level in $\mathrm{Hb}$ Crete carriers, a definitive diagnosis is established by DNA analysis, but sometimes clinically may be change in association with severe beta-thalassemia mutations.

The presence of vaso-occlusion in SCD has been already described since 1910, when Herrick described a young black student with 'anemia with peculiar elongated and sickle-shaped red blood cells. '. In our case hemoglobin $\mathrm{S}$ trait, severe microcytosis and the MRI findings of Avascular necrosis led us to diagnosis of compound Sickle cell disease/hemoglobin Crete. Patients with sickle cell trait have higher total hemoglobin and hemoglobin $\mathrm{F}$ levels, mild splenomegaly, rare Avascular necrosis of the femoral head, and later disease presentation. Bone involvement is the commonest clinical manifestation of sickle cell disease both in the acute setting such as painful vasoocclusive crises, and as a source of chronic, progressive disability such as avascular necrosis. ${ }^{4}$ In our case, the first clinical disease presentation of SCD was avascular necrosis of the knee with bone pain at age of 24years. She was not suspected to have the SCD prior to her presentation. She had never complained of bone pain and $\mathrm{Hb}$ electrophoresis had never been previously performed. Hb Crete ${ }^{5}$ is an electrophoretically neutral, unstable, high oxygen affinity variant. It is caused by the replacement of the nucleotide $\mathrm{G}$ by a $\mathrm{C}$ in codon 129 , leading to the substitution of an alanine by a proline at position $\mathrm{H} 7$ within the $\alpha \mathrm{a} 1 \beta \mathrm{h} 1$ interface, in a region usually not responsible for influencing oxygen binding properties of $\mathrm{Hb}$. Despite extensive functional studies, the mechanism of the instability and increased oxygen affinity of $\mathrm{Hb}$ Crete is not fully understood. It has been shown by functional studies that $\mathrm{Hb}$ Crete is one of the causes of secondary erythrocytosis by increased erythropoietin levels. Our index case and her mother carrier for $\mathrm{Hb}$ Crete did not present with erythrocytosis. This is the first description of a compound heterozygous $\mathrm{Hb}$ Crete $/ \mathrm{Hb}$ $\mathrm{S}$ case, and also the first report on the molecular basis of $\mathrm{Hb}$ Crete.

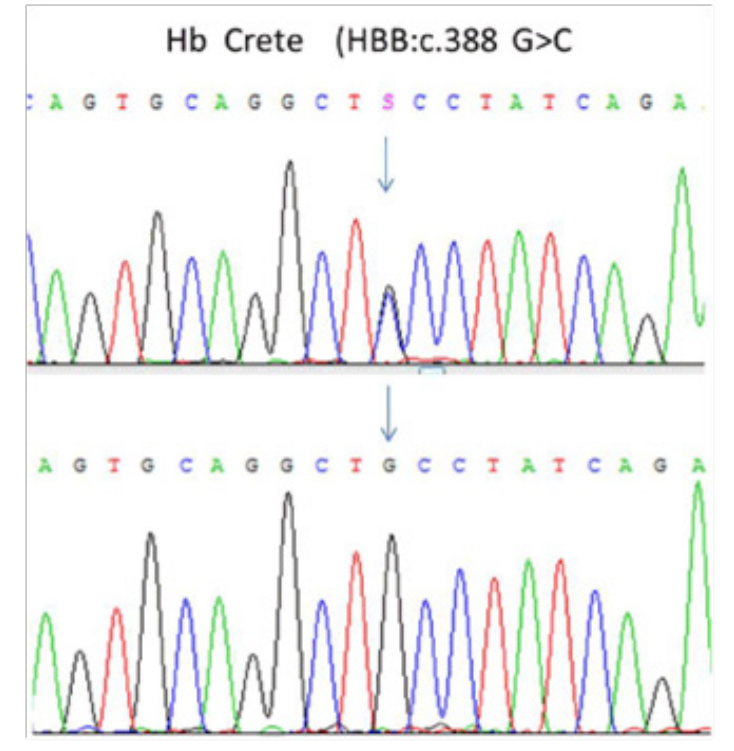

Figure $3 \mathrm{Hb}$ Crete (HBB: c.388 G>C) in Beta sequence analysis.

\section{Acknowledgements}

We would like to thank Dr. Traeger-Synodinos, Department of Medical Genetics, National and Kapodistrian University of Athens, Greece, for the DNA analysis in the proband and her mother.

\section{Conflict of interest}

The author declares no conflict of interest.

\section{References}

1. Angastiniotis M, Bernadette Modell. Global epidemiology of hemoglobin disorders. Ann N Y Acad Sci. 1998;850:251-269.

2. Maniatis A, Bousios T, Nagel RL, et al. Hemoglobin Crete (beta 129 ala leads to pro): a new high-affinity variant interacting with beta $\mathrm{o}$-and delta beta o -thalassemia. Blood. 1979;54(1):54-63.

3. James TN. Homage to James B. Herrick: a contemporary look at myocardial infarction and at sickle-cell heart disease. Circulation. 2000;101(15):1874-1887.

4. Almeida Antonio, Irene Roberts. Bone involvement in sickle cell disease. Br J Haematol. 2005;129(4):482-490.

5. Papassotiriou I, Traeger-Synodinos J, Marden MC, et al. The homozygous state for $\mathrm{Hb}$ Crete [beta129 (H7) Ala-->Pro] is associated with a complex phenotype including erythrocytosis and functional anemia. Blood Cells Mol Dis. 2005;34(3):229-234. 